\title{
Does reflective supervision have a future in English local authority child and family social work?
}

\begin{tabular}{|r|l|}
\hline Journal: & Journal of Children's Services \\
\hline Manuscript ID & JCS-06-2017-0024.R2 \\
\hline Manuscript Type: & Review \\
\hline Keywords: & $\begin{array}{l}\text { supervision, child and family social work, reflection, reflective, practice, } \\
\text { learning and development }\end{array}$ \\
\hline \multicolumn{2}{|l}{} \\
\hline
\end{tabular}

\section{SCHOLARONE \\ Manuscripts}




\title{
Does reflective supervision have a future in English local authority child and family social work?
}

\author{
Abstract \\ Purpose - (1) to discuss the underlying assumption that social workers need reflective \\ supervision specifically, as opposed to managerial or any other form of supervision or \\ support; and (2) to consider whether our focus on the provision of reflective supervision may \\ be preventing us from thinking more broadly and creatively about what support local \\ authority child and family social workers need and how best to provide it. \\ Methodology/approach - Argument based on own research and selective review of the \\ literature \\ Findings - Reflective supervision has no future in local authority child and family social \\ work because (1) there is no clear understanding of what reflective supervision is, (2) there is \\ no clear evidence for is effectiveness, and (3) a sizeable proportion of local authority child \\ and family social workers in England do not receive reflective supervision and many never \\ have.
}

Originality/value - Challenges the received wisdom about the value of reflective supervision and advocates exploring alternative models for supporting best practice in child and family social work 


\section{Introduction}

Supervision is fundamental to the social work profession. Good supervision is said to be one of the most important factors in achieving positive outcomes for children and families and plays a key role in development and retention. And yet, despite the high value placed upon it, the debate around local authority supervision has for many years been characterised in England by a sense of pessimism. Through surveys and other methods, researchers have repeatedly found either that local authority social workers do not receive supervision regularly enough or the supervision they do receive is dominated by management accountability to the exclusion of almost everything else. It has been suggested that reflective supervision can provide a solution to these problems, offering a better approach for managers, practitioners and people who use services alike. If true, this places a serious and significant responsibility on managers - and others - to ensure the conditions for reflective supervision are developed and sustained. On the other hand, perhaps by focusing on reflective supervision, we place too much pressure on managers, miss opportunities to explore how best to support good practice in other ways and mistake cultural and organizational problems for individual ones? Either way, this raises the question - does reflective supervision have a future in local authority child and family social work?

Given the importance of reflective supervision and its conceptual bedfellow, reflective practice, the answer to this question may seem obvious. Of course it does! "Reflective practice is one of the core tenets of the professional social work role" (Houston, 2015 , p. 4). And yet, in recent years, many academics and practitioners have expressed concern about the managerial take-over of professional supervision and how this reduces the possibility and potential for more reflective supervision and practice (Beddoe, 2010). These concerns have led to a growing number of arguments being made about the importance of reflective supervision, to push back the creeping tide of managerialism (Rankine et al, 2017). 
Davys and Beddoe (2010) have argued that supervision needs to be a forum for reflection and learning, Munro (2011) that supervisors should enable social workers to "explore and reflect" (p. 108,) and Fook and Gardner (2007) that supervisors should adopt " $a$ reflective approach... [focusing on] feelings, meanings and interpretations from different perspectives" (p. 25). These arguments suggest that social work supervision is - or should be - a forum for reflecting on thoughts and feelings to achieve better practice and improved outcomes (Ruch, 2005).

In this article, I am not going to address the question of whether reflective supervision has a future in local authority child and family social work because of the managerialist threat. These arguments have been expertly and extensively explored elsewhere (Beddoe, 2010; Rogowski, 2011; Lees et al, 2013). Instead, I am going to discuss the underlying assumption that social workers need reflective supervision specifically, as opposed to managerial or any other form of supervision or support. In addition, I will consider whether our focus on the provision of reflective supervision may be preventing us from thinking more broadly and creatively about what support local authority child and family social workers need and how best to provide it.

Before doing so, it is important to be clear about the limitations of this article. (At least from the author's point of view; the reader may well identify a whole host of other limitations.) Firstly, it only applies to child and family social work in English local authorities. It is not about the supervision provided in charitable or voluntary organisations, health services or other fields of work. Similarly, it is not about supervision in other countries, few of which have a system directly comparable to English local authority social work. Secondly, this article does not provide an extensive and well-balanced review of the supervision literature. There are published examples of those already (Carpenter et al, 2013; 
Dilworth, 2013; O'Donoghue and Tsui, 2015). Thus, the literature presented here has been selected - quite openly - to support the argument and see where it leads.

\section{Reflective supervision has no future in local authority child and family social work because there is no clear and shared understanding of what it is}

There is a prevailing belief among many in the profession that child and family social workers need reflective supervision. Ixer (2010) has even suggested that many "academics and practitioners start from a position that reflection [is important]" (p. 90) and proceed accordingly. For example, Skills for Care (2014) has an "expectation that all social workers will have access to reflective supervision" (p. 2). The British Association of Social Workers (2011) says "Supervision...must provide an ...environment for reflecting on practice" (p. 7). The Department for Education (2015) says that supervisors should "facilitate constant reflective thinking” (p. 4) and Hair (2013) argues that social workers need reflective supervision to practice effectively. And, while Ofsted's framework for inspecting local authority services makes surprisingly few references to supervision (only two in a document of 53 pages), it is clear from actual inspection reports that Ofsted believe in and promote (even if they do not define and describe) the importance of reflection in supervision (e.g. Ofsted, 2015, p. 34; Ofsted, 2016; p. 37; Ofsted, 2017, pp. 2, 7, 24 and 27).

In 2010, Ixer cautioned against "the unquestioning acceptance of...reflection" (p. 75) and argued that "definitions [of reflection] mean different things to different people". Although there has been a "significant debate" about reflection in social work, "very little research has been published...that attempts to define what it is" (ibid, p. 80). Grauel (2002) has similarly argued that supervision itself is "a malleable concept in search of a precise definition" (p. 4). One might reasonably ask whether combining relatively ill-defined ideas about reflection with imprecise definitions of supervision could lead in practice not to greater 
effectiveness but to more confusion for managers and practitioners alike. Of course, the quotation from Grauel is more than 15 years old and the one from Ixer more than five. Since then, how has reflective supervision been defined?

Skills for Care (2014) defines reflective supervision as a "regular collaborative reflection between a service provider... and supervisor that builds on the supervisee's...thoughts, feelings, and values" (p. 5). One local authority supervision policy, selected at random via Google, says that reflective supervision "models [the relationships of] the social worker with the service user...[creating] a culture of intellectual enquiry...empathy and...professional development". Another local authority policy, again selected at random, says that "Supervision...enables reflective practice to occur [by providing] guidance, support and challenge in a formal setting" (2014, p. 3). Morrison's widely used and (deservedly) widely respected ' $4 \times 4 \times 4$ ' model positions 'reflection' as one part of the supervision cycle, following from 'experience' and leading to 'analysis and action planning' (Morrison and Wonnacott, 2010).

These definitions are quite different. The first seems to pre-suppose an understanding of 'reflection'. The second suggests that reflective supervision is analogous to the social worker-service user relationship. The third infers that reflective supervision is a means-to-anend (reflective practice). And the fourth suggests that reflection is one part of supervision, rather than a characteristic of the whole.

These definitional complexities should give us pause for thought. Even if we accept that reflective supervision is necessary for local authority child and family social workers, unless we can agree what it is and what it 'looks like' in practice, we will struggle to understand when and how it is being implemented effectively and how it helps improve practice and outcomes. 


\section{Reflective supervision has no future in child and family social work because there is no clear evidence for its effectiveness}

There is evidence that 'good supervision' is related to some elements of 'good practice', at least in terms of workforce development. For example, workers are more likely to say they want to stay with their current employer if they feel supported by their supervisors (Nissly et al, 2005) and supervision can help practitioners manage the stressful demands of their roles (Davys and Beddoe, 2010, p. 184). These outcomes are clearly worth achieving and likely relate to better practice. Very stressed workers will find it harder to form productive relationships with parents and children and if the service suffers from high turnover and agency rates, it will inevitably prove more difficult to maintain (or create) the conditions for good practice.

But if our primary aims were to reduce worker stress and increase retention, might there be more effective ways of doing so? There are many large organisations in the world and most do not address problems of stress and retention by providing reflective supervision. Might a more creative approach yield better outcomes? ${ }^{1}$ After all, even good supervision does not necessarily reduce stress, although it may help workers cope with it (Forrester et al, 2013, p. 144).

In 2013, Carpenter et al reviewed 690 articles on supervision in child welfare services and concluded that "the evidence base for the effectiveness of supervision in child welfare is surprisingly weak" (p. 1843). This, despite a growing number of articles published on the topic since the 1970s (O’Donoghue and Tsui, 2015, p. 619). Bogo and McKnight (2005) reported similar findings from their review of the literature (see also Bruce and Austin, 2001, and Milne et al, 2008). A recent Delphi study by Beddoe et al (2015) identified several priorities for a future research agenda, one of which was developing an evidence base for the

\footnotetext{
${ }^{1}$ Bringing dogs into the workplace as a method to reduce stress seems a remarkably well-evidenced intervention (Barker et al, 2012).
} 
effectiveness of supervision in improving client outcomes. Egan (2012) made similar findings from Australia, noting the limited empirical data available. The same author (with colleagues) later reported results from a national survey and series of focus groups, suggesting that the provision of professional supervision in contemporary Australian contexts at least is exceptionally challenging (Egan et al, 2016). All these studies point in a similar direction - that we have yet to develop a meaningful and robust evidence base for the effectiveness of any form of supervision in local authority child and family social work, let alone for specific forms of reflective supervision. As noted by Lees (2017), evaluating the influence of reflective supervision on service users, rather than professionals themselves, is a complex task (p. 12). But this is the key challenge, because supervision should not be about supporting practitioners per se, it should be about improving the service provided for children and families.

A recent exception to this is the work of Bostock et al (2017), who found an association between systemic group supervision and the use of more advanced communication skills in practice with families. This evidence is encouraging, albeit we do not know the direction of this association (or if a direction even exists) - perhaps social workers with more advanced communication skills are also more able to have systemic supervision discussions? Equally, it may be that systemic supervision sessions do provide a helpful foundation for more skillful communication with families in the context of statutory child and family social work but this may mean very little for more generic attempts to provide reflective supervision.

There are many good reasons for the weakness of this evidence base. These include the definitional difficulties outlined above and the long chain of causal links and intervening variables that would have to exist to relate what happens in supervision with outcomes for children and families (Fleming and Steen, 2004). Despite these challenges, the lack of 
evidence for its' effectiveness remains a key reason why the future of reflective supervision in local authority child and family social work is far from secure.

\section{Reflective supervision has no future in child and family social work because it has no past and no present either}

Most local authority child and family social workers do not currently receive reflective supervision and most of them never have. ${ }^{2}$ According to Baginsky et al (2010), around 1 in 4 practitioners do not have regular monthly meetings with their managers. Fortunately, it seems more likely now that most local authority child and family social workers do meet on a regular basis with their managers to discuss the families they are working with. During these meetings, social workers typically provide a relatively extensive update about what they have been doing with the family and in some cases - but not all they agree with their manager what they are going what to do next (Author's Own et al, 2016). And yet, although this may meet our expectations for case management, it very often does not match any more complex definitions of supervision, reflective or otherwise (despite the best intentions of managers and social workers). These sessions do not usually involve an evaluation of what the social worker has been doing or a discussion of the social worker's feelings and values. Even less frequently do they include an explicit consideration of the links between how the social worker thinks and feels and what they might do next (between analysis and action).

Such findings are nothing new. Munro (2011) reported in her review of the child protection system in England that for many local authority social workers, "the few supervision opportunities [they have] are dominated by a...focus on performance...throughput, case closure, adhering to timescales and completion of written

\footnotetext{
${ }^{2}$ Possibly apart from when on student placements.
} 
records" (p. 115). In a survey of 280 newly qualified social workers, Manthorpe et al (2015) found supervision sessions were dominated by case management. In the same survey, eightyfour per cent of workers said they used supervision to review their cases compared to just eighteen per cent who said they discussed theoretical approaches to practice. Morrison and Wonnacott (2010) have argued that supervision often serves as a forum for the managerial audit of practice and Baginsky et al (2010) found some senior managers view supervision s a mechanism for gathering information from workers rather than a way of providing support. Turner-Daly and Jack (2017) found most sessions typically focused on case management, leaving only a quarter of social workers in their sample feeling satisfied with their supervision. Across these studies, using a variety of methods and undertaken in a variety of locales, the same message has been reported time and again - although supervision should be used for reflection, analysis and support, it is far more often used merely as a form of case management.

Of course, no-one doubts that local authority child and family social workers need to be accountable for their work and that case management is important. Usually, the argument is made that supervision needs to balance the needs of managers to have oversight and practitioners to engage in reflection discussions about their work. For example, the British Association of Social Workers says that "Supervision...needs to combine a performance management approach with a dynamic, empowering and enabling supervisory relationship" (2011, p. 3) and Morrison (2001) has highlighted the need for supervisors to mediate between the competing functions of supervision appropriately. But this need for combination and mediation surely applies only if some tension exists between different supervisory functions. In cases where supervision has been overtaken by managerialist demands for accountability and case management, so far removed is this from most theoretical descriptions of good supervision, it might be better if we stopped calling it supervision at all. We might instead 
accept the reality that a sizeable proportion of local authority child and family social workers in England do not receive reflective supervision and many never have. ${ }^{3}$

\section{Discussion}

If reflective supervision were essential for good local authority child and family social work practice, then its widespread absence would imply a similar absence of good practice. We would have to accept that despite the hard work and good intentions of local authority child and family social workers up and down the country, many of them are prevented from helping the children and families they work with, because they are not properly supported via reflective supervision to do so.

Providing good supervision for local authority child and family social workers is undoubtedly a complex and challenging task. Depending on which definition is used, supervision might be expected to: help create the conditions for good practice; improve outcomes for families; provide emotional support for workers; offer a space to think and reflect; lead to better decision-making; reduce stress; increase retention; endow workers with critical thinking skills, and more. For example, Clayton (2017) has argued that reflective supervision should help practitioners "find a way through any 'paralysis analysis', to develop...practice knowledge, skills and wisdom; make difficult decisions and...keep children safe" (unpaginated).

But how could any individual manager, no matter how dedicated and skillful, achieve all these things for the five or six workers they supervise and in relation to more than one hundred families $?^{4}$ Of course, even where first-line managers are not providing reflective supervision, this does not mean they are failing to support their workers. On the contrary,

\footnotetext{
${ }^{3}$ At least, not since they were students.

${ }^{4}$ According to a recent Department for Education estimate, the average social work caseload in England is 16.1, a figure that was roundly derided by practitioners on twitter and elsewhere (McNicoll, 2017).
} 
good managers support practitioners in a variety of ways, quite apart from supervision - they help with decision making, provide 'debriefs' and a listening ear after difficult experiences, give expert advice and guidance, create team cultures, manage resources, provide on-the-job training and much, much more.

Perhaps the answer lies in providing more and better training for managers? Might that help increase the quality and quantity of reflective supervision available and secure its future within local authority children's services? In some authorities, the training provided is already extensive, in other places, practically non-existent. But training by itself has a long and poor history of changing behaviour in practice over the medium to long term (Cromwell and Kolb, 2004) and high self-reported satisfaction rates for many training courses should not distract us from this difficulty. As has been said many times before, 'culture eats strategy (including training) for breakfast'. Thus, by itself, providing managers with more training cannot be the whole answer.

Despite the challenges outlined so far, I know many managers who do provide reflective supervision, or at least they try to in the face of difficult organisational contexts. And where reflective supervision is available and working well, it seems probable that at least some practitioners and families do benefit as a result. However, could it be that we focus too heavily on the provision of 'good supervision' and not enough on the provision of 'good support' more generally? By asking, enabling or pressurising managers to provide reflective supervision, we risk reinforcing the idea that 'the problem' lies with incapable individuals, rather than with an incapable system. In other words, that individual managers need to 'get better' at providing reflective supervision to enable a higher quality of practice and if children and families receive a poor service, this results necessarily and at least in part because of poor first line management and supervision. This idea is not so very different from any suggestion that social problems such as increasing numbers of children in public care and 
families involved with the child protection system might be solved solely by training individual social workers to practice more effectively with individual families.

What if, instead of asking whether local authority child and family social workers receive reflective supervision, we asked instead 'how are they supported to provide excellent practice'? Such support would inevitably include good supervision, possibly even reflective supervision, but supervision need not be the whole story.

For the sake of argument, suppose that social workers need three key forms of support - emotional, professional and managerial. Emotional support could include managing (or reducing) the stressful demands of the job and being able to talk about difficult experiences. Professional support could include analysis, critical thinking and decision-making. Managerial support could include case management, adherence to professional standards and working to local policies. To suggest all these elements cannot be provided by one supervisor is not a new idea and the English local authority model of one manager supervising a team of workers is internationally unusual (Mitchell, 2016). Even in England, some models of practice already incorporate more diverse forms of supervision (Goodman and Trowler, 2012). Nevertheless, we can represent these three types of support on the $x, y$ and $z$ axes of a 3D cube, much like we could represent two of them on the traditional $\mathrm{x}$ and $\mathrm{y}$ axes of a graph. Rather than asking how these support needs can be provided for via supervision, we can ask instead - what are the possible ways in which these forms of support can be provided? For example, reducing caseloads would allow social workers more time to think and to process their emotions, mindfulness could promote personal wellbeing (Grant, 2013) and Schwartz rounds facilitate peer learning and emotional containment (Thompson, 2013). 
Once we move away from the idea that one supervisor and one form of supervision needs to meet all these needs, we might be able to have a different kind of discussion. We would also be able to stop 'blaming' local authority managers for responding rationally to the demands of a risk-averse and defensive system by, in many cases if not all, providing case management rather than reflective supervision.

More important than whether social workers receive reflective supervision is the question of whether the supervision they receive is conducive and consistent with the authority's practice model or approach. As Bostock et al (2017) found in their study of five local authorities, group supervision that adhered more closely to a systemic ideal was associated with more advanced communication skills in practice with families. The systemic model of practice places a great deal of emphasis on the importance of verbal (and other) communication with families and so a model of supervision that supports this approach is helpful and consistent. But other models of practice, while not overlooking the importance of good communication, have different emphases. Signs of Safety, for example, highlights the important of being clear about risk and harm. What form of supervision best supports this model? Psychodynamic or relationship-based practice emphasizes the importance of relationships and understanding the self. Reflective supervision may well be most suited to this model of practice (Harvey and Henderson, 2017). Thus, rather than seeing reflective supervision as the most suitable kind for everyone, the more important question for a local authority is - what type of practice do we want and how does our approach to supervision support or inhibit such an approach?

These suggestions are not intended to devalue the importance of high quality, formal supervision - indeed, quite the opposite. They are intended to suggest that supporting social workers may be done even more effectively if we can identify clearly the support needs of social workers in different organisations and how these can be met in different ways. Such an 
approach would also allow us to more properly conceive of supervision not as a forum for helping practitioners per se but ultimately as a way of helping children and families (Harkness and Hensley, 1991). By placing less pressure on managers to provide reflective supervision and creating less expectation that without it, practitioners are missing out, we potentially allow for the opportunity to provide for workers' support needs and improve outcomes for children and families in perhaps even more effective ways.

\section{Conclusion}

Does reflective supervision have a future in local authority child and family social work? Without question, statutory child and family social workers need high levels of support and challenge if they are to help children and families. But do they need reflective supervision? Is it reasonable to ask managers to provide something that is often ill-defined, that lacks a clear evidence base and is very difficult to do, particularly within the context of local authority children's services?

Placing the responsibility for support not on the individual but on the system as a whole could lead to a more diverse range of support options. Rather than mandating monthly one-to-one supervision and expecting managers to provide case management, professional and emotional support, we might instead look to a range of different options to meet the needs of different workers at different times. Perhaps we might even learn to trust the judgement of those practitioners about the kind of support they need at any given time. Counselling could be available for emotional support, alongside reflective learning groups and Schwartz rounds. Coaching, especially based on actual observations of practice, and clinical supervision could provide professional support and help improve practice skills. Peer supervision might provide a degree of both emotional and professional support. Group supervision with clinical input could help improve critical thinking and analysis. Once we 
know more about the factors that support different models of good practice (Bostock et al, 2017), perhaps we might find that reflective supervision and supervision in general will come to seem less important. Not because social workers do not need support but precisely because they do.

\section{$\underline{\text { References }}$}

1. Authors Own (2016)

2. Baginsky, M., Moriarty, J., Manthorpe, J., Stevens, M., MacInnes, T. and Nagendran, T. (2010) Social workers' workload survey: messages from the frontline: findings from the 2009 survey and interviews with senior managers. Department for Children, Schools and Families. Available at:

http://dera.ioe.ac.uk/1945/1/SWTF\%20Workload\%20Survey\%20(final).pdf [Accessed April 2017].

3. Barker, R., Knisely, J., Barker, S., Cobb, R. and Schubert, C. (2012) Preliminary investigation of employee's dog presence on stress and organizational perceptions. International Journal of Workplace Health Management, 5(1), pp. 15 - 30.

4. Beddoe, L. (2010) Surveillance or Reflection: Professional Supervision in 'the Risk Society'. British Journal of Social Work, 40(4), pp. 1279 - 1296.

5. Beddoe, L., Karvinen-Niinikoski, S., Ruch, G. and Ming-sum Tsui (2015) Towards an International Consensus on a Research Agenda for Social Work Supervision: Report on the First Survey of a Delphi Study. British Journal of Social Work, 6(1), pp. 1568 $-1586$.

6. Bogo, M. and McKnight, K. (2006) Clinical Supervision in Social Work. The Clinical Supervisor, 24(1-2), pp. $49-67$. 
7. Bostock, L., Forrester, D., Patrizo, L., Godfrey, T., Zonouzi, M. (2017) Scaling and deepening the Reclaiming Social Work model: Evaluation report. Department for Education, London

8. British Association of Social Workers (2011) UK Supervision Policy. Available at: http://cdn.basw.co.uk/upload/basw 73346-6.pdf [Accessed April 2017].

9. Bruce, E. and Austin, M. (2001) Social work supervision. The Clinical Supervisor, 19(2), pp. $85-107$.

10. Carpenter, J., Webb, C. and Bostock, L. (2013) The surprisingly weak evidence base for supervision: Findings from a systematic review of research in child welfare practice. Child and Youth Services Review, 35, pp. 1843 - 1853.

11. Clayton, S. (2017) Reflective supervision: the cornerstone of good social work practice. Available at: https://www.rip.org.uk/news-and-views/blog/reflective$\underline{\text { supervision-the-cornerstone-of-good-social-work-practice/ }}$

12. Cromwell, S. and Kolb, J. (2004) An examination of work-environment support factors affecting transfer of supervisory skills training to the workplace. Human Resource Development Quarterly, 15(4), pp. 449 - 471.

13. Davys, A. and Beddoe, L. (2010) Best Practice in Professional Supervision. Jessica Kingsley, London.

14. Department for Education (2015) Knowledge and skills statements for practice leaders and practice supervisors. Available at: https://www.gov.uk/government/uploads/system/uploads/attachment_data/file/478111 /Knowledge_and_skills_statements_for_practice_leaders_and_practice_supervisors.p df [Accessed May 2017].

15. Dilworth, S. (2013) Finding a way forward: a literature review on the current debates around clinical supervision. Contemporary Nursing, 45(1), pp. $22-32$. 
16. Egan, V. (2012) Australian social work supervision practice in 2007. Australian Social Work, 65(2), pp. $171-184$.

17. Egan, R., Maidment, J. and Connolly, M. (2016) Who is Watching Whom? Surveillance in Australian Social Work Supervision. British Journal of Social Work, 6(1), pp. $1617-1635$.

18. Fleming, I. and Steen, L. (2004) 'Introduction' in I Fleming and L Steen (eds) Supervision and clinical psychology: theory, practice and perspectives (second edition). Routledge, London.

19. Fook, J. and Gardner, F. (2007) Practicing Critical Reflection: A Resource Handbook. Open University Press, Maidenhead.

20. Forrester, D., Westlake, D., McCann, M., Thurnham, A., Shefer, G., Glynn, G. and Killian, M. (2013) Reclaiming Social Work? An Evaluation of Systemic Units as an Approach to Delivering Children's Services. Final report of a comparative study of practice and the factors shaping it in three local authorities. Available at: https://www.beds.ac.uk/ data/assets/pdf file/0011/258491/finalreport-RSWv319072013.pdf [Accessed April 2017]

21. Grant, L. (2013) Heart and Minds: Aspects of Empathy and Wellbeing in Social Work Students. Social Work Education: The International Journal, 33(3), pp. 338 - 352.

22. Goodman, S. and Trowler, I. (2012) Social Work Reclaimed. Jessica Kingsley, London.

23. Grauel, T. (2002) Professional Oversight: The Neglected Histories of Supervision. In M. McMahon and W. Patten (eds) Supervision in the Helping Professions, A Practical Approach. Prentice Hall, New South Wales. 
24. Hair, H. (2013) The Purpose and Duration of Supervision, and the Training and Discipline of Supervisors: What Social Workers Say They Need to Provide Effective Services. British Journal of Social Work, 43(8), pp. 1562 - 1588.

25. Harkness, D. and Hensley, H. (1991) Changing the Focus of Social Work Supervision: Effects on Client Satisfaction and Generalized Contentment. Social Work, 36(6), pp. $506-512$.

26. Harvey, A. and Henderson, F. (2017) Reflective supervision for child protection practice. Researching beneath the surface. In M. Bower and R. Solomon (eds) What social workers need to know: A psychoanalytical approach. Routledge, London.

27. Houston, S. (2015) Reflective Practice. A model for supervision and practice in social work. Available at: https://niscc.info/storage/resources/86085-printersreflectivepracticefullversionfinal-19-05-2015-lr.pdf [Accessed May 2017].

28. Ixer, G. (2010) 'There's no such thing as reflection' ten years on. Journal of Practice Teaching and Learning, 10(1), DOI: 10.1921/jpts.v10i1.238

29. Lees, A., Meyer, E. and Rafferty, J. (2013) From Menzies Lyth to Munro: The Problem of Mangerialism. British Journal of Social Work, 43(3), pp. $542-558$.

30. Lees, A. (2017) Evaluation of Reflective Practice Group Project: Brighton and Hove Children's Services Preliminary Report. Available at: http://www.cfswp.org/perch/resources/cfswp-rpg-evaluation-dr-a-lees-2017.pdf [Accessed September 2017].

31. McNicoll, A. (2017) Government reveals average social worker caseload. Available at: http://www.communitycare.co.uk/2017/02/16/government-reveals-average-socialworker-caseload/ [Accessed June 2017].

32. Manthorpe, J., Moriarty, J., Hussein, S., Stevens, M. and Sharpe, E. (2015) Content and Purpose of Supervision in Social Work Practice in England: Views of Newly 
Qualified Social Workers, Managers and Directors. British Journal of Social Work, 45(1), pp. $52-68$.

33. Milne, D., Aylott, H., Fitzpatrick, H. and Ellis, M. (2008) How does clinical supervision work? Using a 'best evidence' approach to construct a basic model of supervision. The Clinical Supervisor, 27(2), pp. 170 - 190.

34. Mitchell, B. (2016) Looking at England and Norway. Sanctuary Social Work News, July-September, p. $26-27$.

35. Morrison, T. (2001) Staff supervision in social care: Making a real difference for staff and service users. Pavilion, Brighton.

36. Morrison, T. and Wonnacott, J. (2010) Supervision: Now or Never: Reclaiming Reflective Supervision in Social Work. Available at: http://www.intrac.co.uk/supervision-now-or-never/ [Accessed April 2017].

37. Munro, E. (2011) The Munro Review of Child Protection: Final Report. A childcentred system. Available at: https://www.gov.uk/government/uploads/system/uploads/attachment data/file/175391 /Munro-Review.pdf [Accessed April 2017].

38. Nissly, J., Mor Barak, M. and Levin, A. (2005) Stress, support and workers' intentions to leave their jobs in public child welfare. Administration in Social Work, 29(1), pp. $79-100$.

39. O'Donoghue, K. and Ming-sum Tsui (2015). Social Work Supervision Research (1970-2010): The Way We Were and the Way Ahead. British Journal of Social Work, 45 (2), pp. 616-633.

40. Ofsted (2015) London Borough of Enfield. Available at: https://reports.ofsted.gov.uk/sites/default/files/documents/local_authority_reports/enfi 


\section{eld $/ 050$ Single $\% 20$ inspection $\% 20$ of $\% 20$ LA $\% 20$ children $\% 27 \mathrm{~s} \% 20$ services $\% 20$ and $\%$}

20review\%20of $\% 20$ the $\% 20$ LSCB $\% 20$ as\%20pdf.pdf [Accessed September 2017].

41. Ofsted (2016) Slough Borough Council. Available at: https://reports.ofsted.gov.uk/sites/default/files/documents/local_authority_reports/slou gh/052 Single $\% 20$ inspection $\% 20$ of $\% 20$ LA $\% 20$ children $\% 27 \mathrm{~s} \% 20$ services $\% 20$ and $\%$ 20review\%20of\%20the\%20LSCB\%20as\%20pdf.pdf [Accessed September 2017].

42. Ofsted (2017) Stockport Metropolitan Borough Council. Available at: https://reports.ofsted.gov.uk/sites/default/files/documents/local_authority_reports/stoc kport $/ 052$ Single $\% 20$ inspection $\% 20$ of $\% 20$ LA $\% 20$ children $\% 27 \mathrm{~s} \% 20$ services $\% 20$ and \%20review $\% 20$ of $\% 20$ the $\% 20$ LSCB.pdf [Accessed September 2017].

43. Rankine, M., Beddoe, L., O’Brien, M. and Fouche, C. (2017) What's your agenda? Reflective supervision in community-based child welfare services. European Journal of Social Work, DOI: 10.1080/13691457.2017.1326376

44. Rogowski, S. (2012) Social Work with Children and Families: Challenges and Possibilities in the Neo-Liberal World. British Journal of Social Work, 42(5), pp. 921 $-940$.

45. Ruch, G. (2005) Relationship-based practice and reflective practice: holistic approaches to contemporary child care social work. Child and Family Social Work, 10(2), pp. $111-123$.

46. Skills for Care (2014) Developing social workers' practice. Core principles for employers providing a flexible CPD approach for social workers. Available at: http://www.skillsforcare.org.uk/Document-library/Socialwork/CPD/CP\%20CPD\%20refresh.pdf [Accessed May 2017].

47. Thompson, A. (2013) How Schwartz rounds can be used to combat compassion fatigue? Nursing Management, 20(4), pp. 16 - 20. 
1

2

3

4

5

6

7

8

9

10

11

12

13

14

15

16

17

18

19

20

21

22

23

24

25

26

27

28

29

30

31

32

33

34

35

36

37

38

39

40

41

42

43

44

45

46

47

48

49

50

51

52

53

54

55

56

57

58

59

60

48. Turner-Daly, B. and Jack, G. (2017) Rhetoric vs. reality in social work supervision: the experiences of a group of child care social workers in England. Child and Family Social Work, 22(1), pp. $36-46$. 


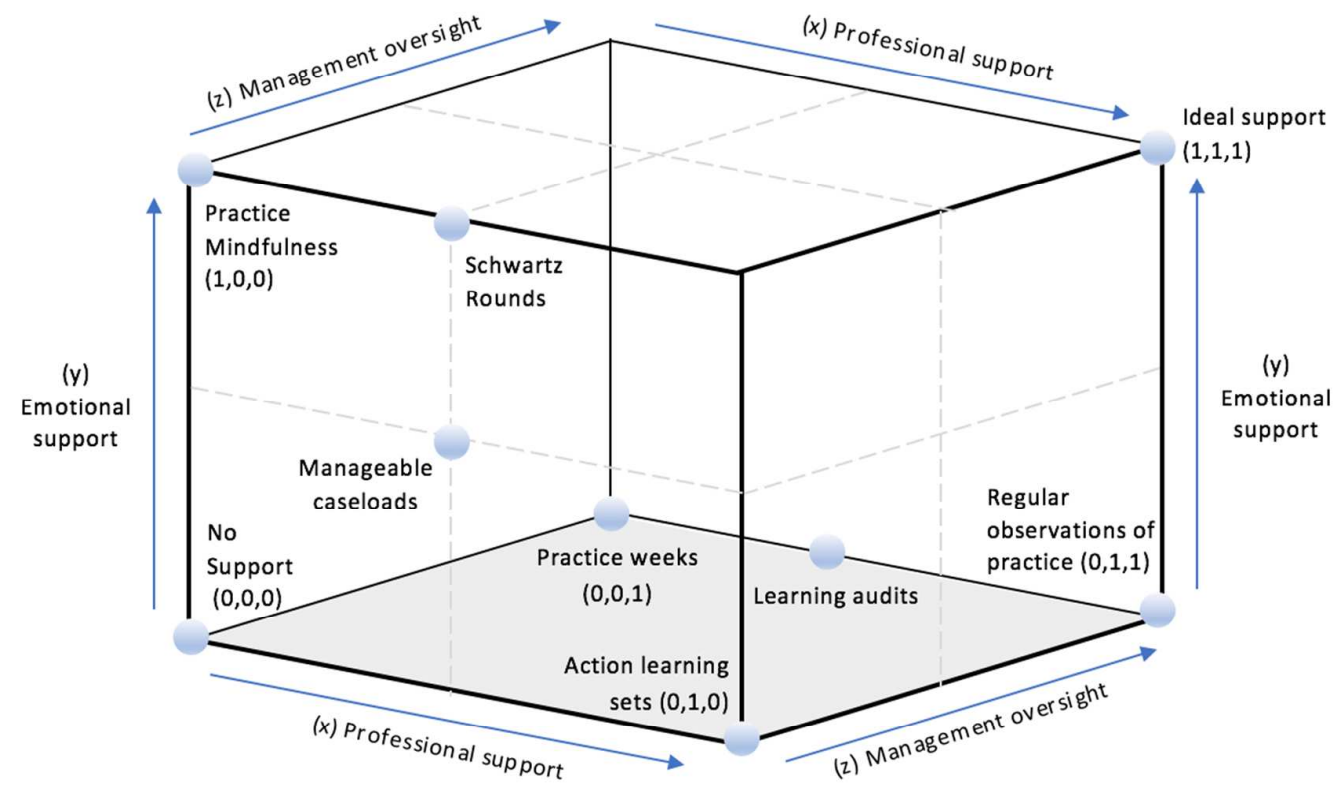

Figure 1: A 3D model of three key forms of support for social workers and an estimation of how different activities (not just supervision) might provide for them. 